\title{
PHYTOPLANKTON COMMUNITY STRUCTURE AND ITS RELATIONSHIP WITH ENVIRONMENTAL FACTORS IN TAIHU NATIONAL WETLAND PARK IN NORTHEAST CHINA
}

\author{
CHAI, Y. H. ${ }^{1 \#}-$ YU, T. Y. ${ }^{\#}-\mathrm{SUN}, \mathrm{X}^{3}-\mathrm{WEI}, \mathrm{H}^{4^{*}}-\mathrm{YU}, \mathrm{H} . \mathrm{X} .^{2^{*}}$ \\ ${ }^{1}$ Aulin College, Northeast Forestry University, Harbin 150040, China \\ ${ }^{2}$ College of Wildlife and Protected Area, Northeast Forestry University, Harbin 150040, China \\ ${ }^{3}$ College of Fisheries and Life Science, Dalian Ocean University, Dalian 116023, China \\ ${ }^{4}$ School of Business, Beijing Union University, Beijing 100101, China \\ ${ }^{\#}$ Co-first authors \\ These authors contributed to the work equally. \\ ${ }^{*}$ Corresponding authors \\ e-mail: heng.wei@buu.edu.cn (Wei, H.); china.yhx@163.com (Yu, H.X.) \\ (Received 28 $8^{\text {th }}$ Apr 2021; accepted 29 Jul 2021)
}

\begin{abstract}
In order to understand the community structure of phytoplankton and its relationship with environmental factors in Taihu National Wetland Park in northeast China, a study was conducted in Taihu in September 2020. The results showed that there were 39 species of phytoplankton belonging to 27 genera and 6 phyla, among which Chlorophyta was the most abundant (20 species). The abundance and biomass of $5 \#$ and $6 \#$ sampling sites were significantly higher than other sampling sites, which may be caused by eutrophication. In Taihu National Wetland Park, the dominant species were Merismopedia minima, Aphanizomenon flosaquae, Synedra acus, Synura.sp and Scenedesmus quadricauda. Phytoplankton community structure in autumn in Taihu National Wetland Park were mainly influenced by $\mathrm{pH}, \mathrm{NO}_{3}{ }^{-} \mathrm{N}$, and water temperature. This research can provide a scientific basis for biodiversity protection and pollution control in Taihu National Wetland Park.
\end{abstract}

Keywords: phytoplankton, biodiversity, richness, correlation, spatiality

\section{Introduction}

According to Chalar (2009), the Earth's ecosystem is experiencing an unprecedented rate of biodiversity loss as a result of global climate change, eutrophication, and overexploitation of natural resources. Aquatic ecosystems especially lakes are vulnerable and the loss of biodiversity may have catastrophic consequences, such as algal blooms (Cardinale et al., 2012; Weyhenmeyer et al., 2013). Phytoplankton, which forms the base of food web in lakes, is particularly sensitive to variations in environmental factors (Mulvenna et al., 2012; Weyhenmeyer et al., 2013). Their community structure-like composition, abundance and biomass are affected by biotic factors, as well as abiotic factors like temperature, salinity, $\mathrm{pH}$, nutrients and electrical conductivity (Oduor and Schagerl, 2007; Schagerl and Oduor, 2008; Oren, 2011). Investigations of phytoplankton communities in different ecosystem types have been carried out by different researchers in China (Ma and Yu, 2013; Sun et al., 2019; Ma et al., 2021).

Taihu National Wetland Park is located in the east of Tailai County. The wetland park receives water from direct precipitation. It also receives inflow from domestic sewage and industrial wastewater from Tailai County (Lin, 2002). Before 1990's, the wetland 
park was seriously polluted because of the inflow of wastewater from Tailai paper mill. However, after the paper mill was banned from discharging its wastewater into the wetland, the water quality of Taihu National Wetland Park improved to a certain extent. In the recent years, the development of tourism and the influence of nearby residents' activities as a result of increase in human population have led to deterioration of the water quality in the wetland. As it currently stands, the water quality of the lake is in deplorable state. Although studies on planktons have been conducted in most of the aquatic systems in China (Sun et al., 2010; Yang et al., 2011; Shi et al., 2015), work of community structure of phytoplankton and their relationship to environmental variable of Taihu National Wetland Park is, however, lacking. So, this study will help fill the lacunae in scientific understanding of the community structure of this unique ecosystem. Moreover, this study will provide some reference for ecological restoration and management of the Wetland Park.

\section{Materials and methods}

\section{Study area and sampling sites}

The study was conducted in Taihu National Wetland Park which lies on E123 ${ }^{\circ} 5^{\prime} 14.17^{\prime \prime} \sim \mathrm{E} 123^{\circ} 29^{\prime} 00.97^{\prime \prime}, \mathrm{N} 46^{\circ} 24^{\prime} 12.10^{\prime \prime} \sim \mathrm{N} 46^{\circ} 21^{\prime} 15.10^{\prime \prime}$ in northeast China (Chen et al., 2018). Taihu National Wetland Park covers an area of approximately $1365 \mathrm{hm}^{2}$ and it lies in an area which is under the influence of temperate continental monsoon climate zone. This study area receives an annual average precipitation of $360 \mathrm{~mm}$ with an annual mean temperature of about $4.2^{\circ} \mathrm{C}$. The wetland is important for water supply, flood control, tourism and recreation, and aquaculture.

All samples were collected 3 times from 8 sampling sites of Taihu National Wetland Park in September (autumn) in 2020. The site included 1\# located in the ditch close to Taihu, sites 2\# and 3\# were located in the sewage treatment plant, site 4\# was located in the "reclaimed water" inlet of the sewage treatment plant, and sites 5-8\# were located in the middle of the Taihu National Wetland Park (Table 1, Figure 1).

Table 1. Location of sampling sites in Taihu National Wetland Park

\begin{tabular}{c|c|c|c}
\hline Sampling sites & Coordinate & Sampling sites & Coordinate \\
\hline $1 \#$ & $46^{\circ} 21^{\prime} 56^{\prime \prime} \mathrm{N} 123^{\circ} 26^{\prime} 32^{\prime \prime} \mathrm{E}$ & $5 \#$ & $46^{\circ} 23^{\prime} 03^{\prime \prime} \mathrm{N} 123^{\circ} 26^{\prime} 14^{\prime \prime} \mathrm{E}$ \\
$2 \#$ & $46^{\circ} 22^{\prime} 18^{\prime \prime} \mathrm{N} 123^{\circ} 26^{\prime} 42^{\prime \prime} \mathrm{E}$ & $6 \#$ & $46^{\circ} 23^{\prime} 04^{\prime \prime} \mathrm{N} 123^{\circ} 26^{\prime} 20^{\prime \prime} \mathrm{E}$ \\
$3 \#$ & $46^{\circ} 22^{\prime} 25^{\prime \prime} \mathrm{N} 123^{\circ} 26^{\prime} 15^{\prime \prime} \mathrm{E}$ & $7 \#$ & $46^{\circ} 23^{\prime} 02^{\prime \prime} \mathrm{N} 123^{\circ} 27^{\prime} 13^{\prime \prime} \mathrm{E}$ \\
$4 \#$ & $46^{\circ} 22^{\prime} 20^{\prime \prime} \mathrm{N} 123^{\circ} 26^{\prime} 50^{\prime \prime} \mathrm{E}$ & $8 \#$ & $46^{\circ} 23^{\prime} 30^{\prime \prime} \mathrm{N} 123^{\circ} 26^{\prime} 51^{\prime \prime} \mathrm{E}$ \\
\hline
\end{tabular}

\section{Sample collection and analysis}

At each sampling site water temperature (WT), $\mathrm{pH}$, ammonia nitrogen $\left(\mathrm{NH}_{4}^{+}-\mathrm{N}\right)$ and nitrate nitrogen $\left(\mathrm{NO}_{3}^{-}-\mathrm{N}\right)$ were measured using a Multi parameter water quality analyzer (YSI 6600, YSI Inc., USA) while water transparency (SD) was determined using a $20 \mathrm{~cm}$ Secchi disk. Whole water samples from the same site were collected and transported to the laboratory for analysis of total nitrogen (TN), total phosphorus (TP) and chemical oxygen demand $\left(\mathrm{COD}_{\mathrm{Cr}}\right)$. Total nitrogen $(\mathrm{TN})$, TP and $\mathrm{COD}_{\mathrm{Cr}}$ were analyzed according to the standard methods for China (MEP (Ministry of Environmental Protection, 2002). 


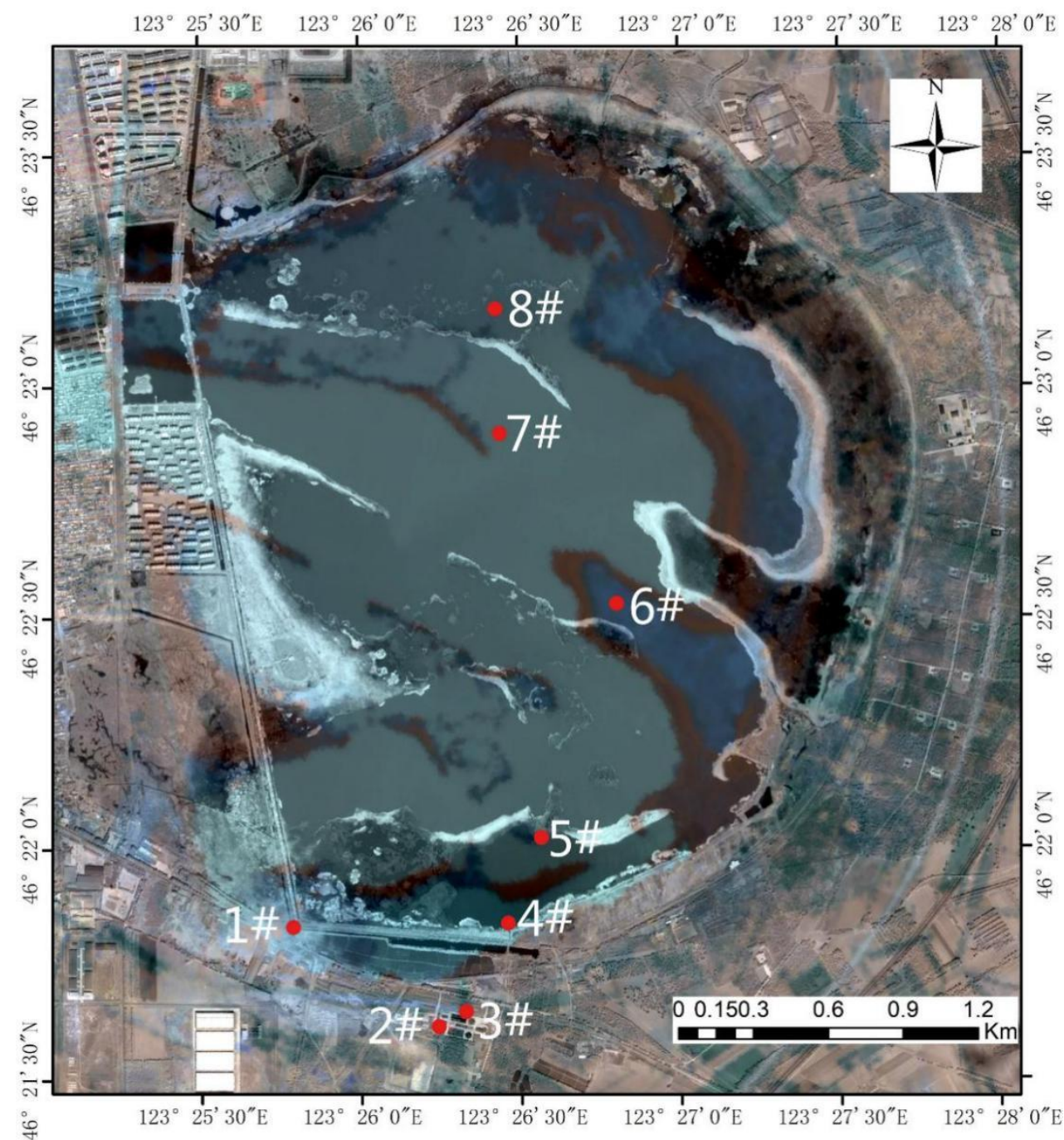

Figure 1. Map of Taihu National Wetland Park Showing the distribution of sampling sites

Replicates of phytoplankton samples (1 L at each site) were collected, put in a labeled bottle and immediately fixed with Lugol's solution. The phytoplankton samples were allowed to sediment for $48 \mathrm{~h}$ and then concentrated to $30 \mathrm{~mL}$. Phytoplankton were identified by referring to the identification key of $\mathrm{Hu}$ (2006) and counted using an inverted microscope (Leica Microsystems, German) at 400× magnification. Phytoplankton diversity, richness and dominance were determined for each sampling sites using number of taxa, total number of individuals per taxa and relative abundance of each taxon over the sampling period respectively. Biomass of the phytoplankton was computed by dividing wet weight $(\mathrm{mg})$ obtained from length-weight relation of the species to the volume of water (L) filtered (Sun et al., 2010). Shannon-Weaver diversity index (Shannon and Weiner 1948) was used to calculate diversity as follows:

$$
\mathrm{H}=-\sum\left[\left(\frac{\mathrm{n}}{\mathrm{N}}\right) *\left(\ln \frac{\mathrm{n}}{\mathrm{N}}\right)\right]
$$

where $\mathrm{n}=$ number of individuals of a taxon; $\mathrm{N}=$ total number of individual in a site. This index takes into account both the numbers of taxa and their relative abundance. 
Taxon richness was calculated using Margalefs Index (D) (Clarke and Warwick, 1994):

$$
\mathrm{D}=(\mathrm{S}-1) / \ln \mathrm{N}
$$

where $\mathrm{S}$ is the total number of species, $\mathrm{N}$ is the total number of individuals of all species, and $P_{i}$ is the proportion of the number of individuals of the $\mathrm{i}$-th species in the total number of individuals.

Species dominance was computed according to the formula proposed by as follows:

$$
y=f_{i} \times P_{i}
$$

where, $y$ is the dominance, $P_{i}$ is the proportion of the $i$-th species in the total number of individuals, $f_{i}$ is the frequency of the species at each sampling time. When $y>0.02$, it is defined as the dominant species. Table 2 below shows the water quality evaluating criteria based on the diversity indices.

Table 2. Diversity Index Water Quality Evaluation Standard

\begin{tabular}{c|c|c|c}
\hline Index & \multicolumn{3}{|c}{ Pollution index } \\
\hline Shannon-Weaver Diversity index $\left(H^{\prime}\right)$ & $0-1$ Heavy & $1-3$ Medium & $>3$ Light \\
Margalef Richness index $(D)$ & $0-1$ Heavy & $1-3$ Medium & $>3$ Light \\
\hline
\end{tabular}

\section{Data analyses}

The data was analyzed using SPSS 17.0 (SPSS, 2008) and Microsoft Excel window 2007. Before analysis, the Kolmogorov-Smirnov method was used to test whether data were normally distributed, and the Bartlett test was performed to assess the homogeneity of variance. The data that did not meet the normality test was log transformed. One-way ANOVA was used to test the difference of the measures variable (environmental variables, phytoplankton diversity, richness and dominance) among sites. Relationships between phytoplankton species and environment variables were analyzed using the detrended correspondence analysis and redundancy analysis (RDA) using CANOCO 4.5 software (Microcomputer Power, New York, USA). Monte Carlo simulations with 499 permutations were used to test the significance of the physical-chemical variables in explaining the biomass of phytoplankton functional groups data in the RDA. Figures were drawn using Microsoft excel.

\section{Results}

\section{Physical-chemical variables}

The mean spatial values of physical-chemical factors recorded among the sampling sites within the study period are presented in Table 3 . The average WT was $18.62{ }^{\circ} \mathrm{C}$ with the relative highest value of $20^{\circ} \mathrm{C}$ being recorded in site $1 \#$. The values of $\mathrm{pH}$ measured in this wetland park were in the side of alkalinity (basic). TN, TP, $\mathrm{NH}_{4}{ }^{+}-\mathrm{N}, \mathrm{NO}_{3}{ }^{-} \mathrm{N}$ and CODcr differed significantly among the sites. TN, TP, $\mathrm{NH}_{4}{ }^{+}-\mathrm{N}$ and $\mathrm{NO}_{3}{ }^{-}-\mathrm{N}$ were significantly higher in site $2 \#$ with a mean value of $6.62,0.67,11.26$ and $1.23 \mathrm{mg} / \mathrm{L}$, respectively. Similarly, CODcr was significantly higher in site 2\# (Table 2). 
Classification which was done according to the Environmental Quality Standard for Surface Water (GB3838-2002), showed that with exception of $\mathrm{NO}_{3}{ }^{-} \mathrm{N}$ which belongs to Class IV water quality, all the remaining measured variables belong to Class $\mathrm{V}$ water quality.

Table 3. Water quality measurement results of Taihu National Wetland Park (unit: except water temperature and $\mathrm{pH}$, the rest are all $\mathrm{mg} / \mathrm{L}$ )

\begin{tabular}{c|c|c|c|c|c|c|c}
\hline Sampling site & $\left.\mathbf{W T} \mathbf{(}^{\mathbf{}} \mathbf{C}\right)$ & $\mathbf{p H}$ & $\mathbf{N H}_{4}^{+}-\mathbf{N}$ & $\mathbf{N O}_{3}^{-}-\mathbf{N}$ & $\mathbf{T N}$ & $\mathbf{T P}$ & $\mathbf{C O D}_{\mathbf{C r}}$ \\
\hline $1 \#$ & 20 & 8.74 & 1.26 & 0.62 & 1.67 & 0.26 & 22.8 \\
$2 \#$ & 18 & 8.25 & 11.26 & 1.23 & 6.62 & 0.67 & 29.6 \\
$3 \#$ & 18 & 8.93 & 3.26 & 0.53 & 4.88 & 0.34 & 22.3 \\
$4 \#$ & 19 & 9.17 & 2.21 & 0.59 & 4.82 & 0.27 & 20.2 \\
$5 \#$ & 19 & 9.03 & 1.22 & 0.52 & 4.92 & 0.25 & 19.3 \\
$6 \#$ & 19 & 9.32 & 0.96 & 0.39 & 3.46 & 0.18 & 2.6 \\
$7 \#$ & 18 & 9.28 & 1.09 & 0.42 & 3.13 & 0.21 & 2.2 \\
$8 \#$ & 18 & 9.11 & 1.06 & 0.46 & 2.95 & 0.18 & 2.3 \\
\hline Average value & 18.62 & 8.98 & 2.79 & 0.59 & 4.06 & 0.30 & 15.2 \\
GB3838-2002 & & & $\mathrm{V}$ & $\mathrm{IV}$ & $\mathrm{V}$ & $\mathrm{V}$ & $\mathrm{V}$ \\
\hline
\end{tabular}

\section{Phytoplankton species composition and their spatial distribution}

In the current study, a total of 39 species of phytoplankton belonging to 27 genera and in 6 classes were identified. Chlorophyta was the most with 20 species, accounting for $51.28 \%$; bacillariophyta was the second with 11 species accounting for $28.21 \%$; Cyanophyta has 4 species, accounting for $10.26 \%$; Euglenophyta has 2, accounting for 5.13\%; Chrysophyta and cryptophyta had 1 each which accounted for $5.13 \%$ altogether.

Spatially, sampling site 5\# had the highest number of species (31 species), followed by $6 \#$ ( 24 species) and the site with the least species number was 1\# (Figure 2). The abundance and biomass of phytoplankton measured in the Taihu National Wetland Park was significantly different among sampling sites (Figure 3). There was spatial significant difference in abundance and biomass distribution among sampling sites (Figure 3). The abundance of the phytoplankton ranged between $141.6 \times 10^{4}$ ind./L $\sim 4311.6 \times 10^{4}$ ind./L, with the highest value of $4311.6 \times 10^{4}$ ind./L recorded in site $5 \#$ while the least $\left(141.6 \times 10^{4}\right.$ ind./L) was measured at site $1 \#$. The phytoplankton biomass measured ranged between $0.39 \mathrm{mg} / \mathrm{L}$ and $21.24 \mathrm{mg} / \mathrm{L}$, with the highest value of $21.24 \mathrm{mg} / \mathrm{L}$ measured at site $6 \#$ and the lowest of $0.39 \mathrm{mg} / \mathrm{L}$ at site $1 \#$.

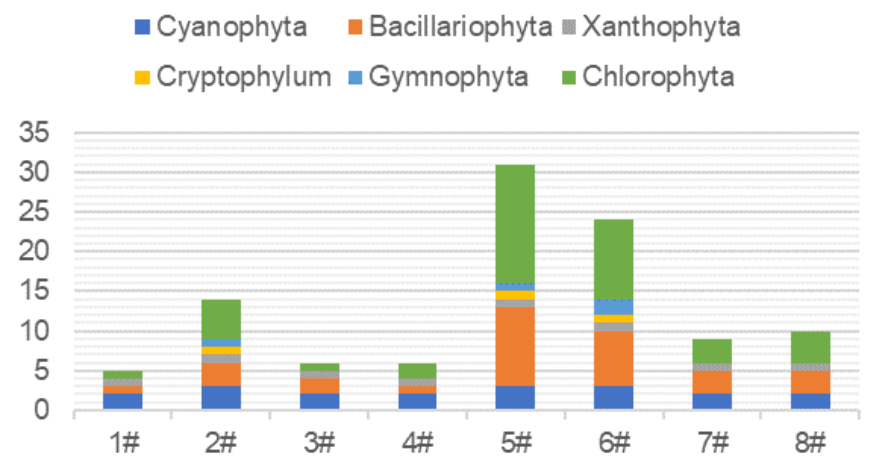

Figure 2. Number of phytoplankton species at sampling sites in Taihu National Wetland Park in autumn 


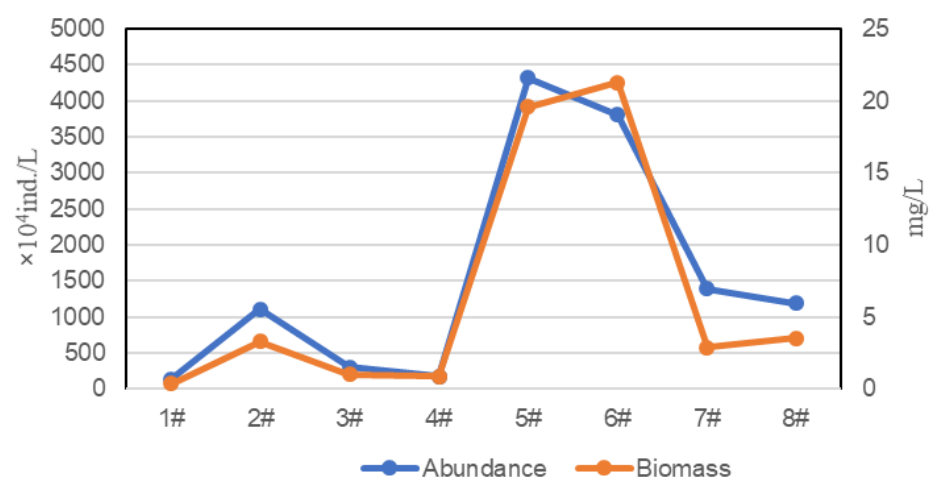

Figure 3. Phytoplankton abundance and biomass in Taihu National Wetland Park

\section{Phytoplankton species diversity, richness and dominance}

Phytoplankton community attributes such as diversity, richness and dominance often give important clues of the functional status or health of aquatic system. From the results, Shannon Weaver index ranged from 1.041 to 2.371 in the study area while; Margalef richness index ranged from 0.838 to 3.665 (Table 4 and Figure 4). Spatially, site 5\# had the highest value of phytoplankton diversity of (2.371) while site 1\# with a value of 1.041 was the least. Similarly, the taxon richness was significant higher in site $5 \#$ with a value of 3.665 and the least was observed in site $1 \#$ with a value of 0.838 . Moreover, it is apparent that, Taihu National Wetland Park belongs to medium-heavy pollution type (Table 4).

Table 4. The diversity index and pollution evaluation of phytoplankton sampling points in Taihu National Wetland Park in autumn

\begin{tabular}{c|c|c|c|c}
\hline Sampling site & $\boldsymbol{H}^{\prime}$ & Assessment & $\boldsymbol{D}$ & Assessment \\
\hline $1 \#$ & 1.041 & Medium pollution & 0.838 & Heavy pollution \\
$2 \#$ & 1.248 & Medium pollution & 1.903 & Medium pollution \\
3\# & 1.492 & Medium pollution & 0.901 & Heavy pollution \\
$4 \#$ & 1.171 & Medium pollution & 1.001 & Medium pollution \\
$5 \#$ & 2.371 & Medium pollution & 3.665 & Light pollution \\
$6 \#$ & 2.229 & Medium pollution & 2.853 & Medium pollution \\
$7 \#$ & 1.045 & Medium pollution & 1.134 & Medium pollution \\
8\# & 1.287 & Medium pollution & 1.305 & Medium pollution \\
Average value & 1.486 & Medium pollution & 1.7 & Medium pollution \\
\hline
\end{tabular}

Dominant species are defined by the dominance $y>0.02$. The dominant species and their dominance of phytoplankton in Taihu National Wetland Park are shown in Table 5. In this study, the dominant species were Schizosaccharum tenuiflorum, filamentous alga bloom and Scenedesmus giraldii, belong to the indicator algae of eutrophic water body, and their dominance degrees are $0.675,0.041$ and 0.058 , respectively.

When the occurrence of a species is greater than 65 , then the species is regarded as a common species (Occurrence frequency $>65 \%$ ). Table 6 shows the common species recorded during the study period in Taihu National Wetland Park. Seven common species belonging into 4 classes were observed in the wetland. These species are Merismopedia minima, Aphanizomenon flosaquae, Cyclotella meneghiniana and Scenedesmus quadricauda. These species are all indicator of eutrophic water body. 


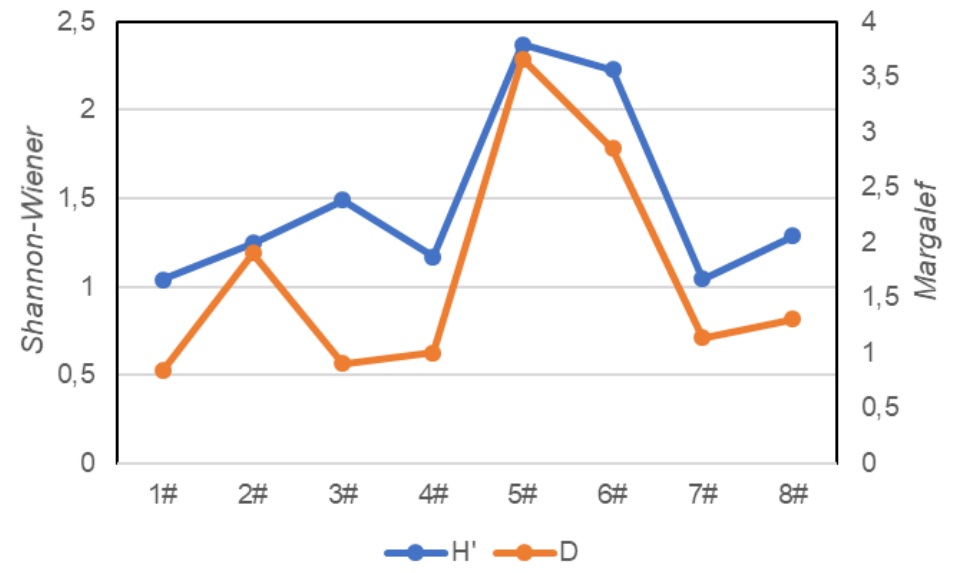

Figure 4. Phytoplankton taxon characteristics determined at the sites in the Taihu National Wetland Park

Table 5. The dominant species of phytoplankton in Taihu National Wetland Park in autumn

\begin{tabular}{c|c|c}
\hline Dominant species & Occurrence frequency & Dominance \\
\hline Merismopedia minima & 1 & 0.675 \\
Aphanizomenon flosaquae & 1 & 0.041 \\
Synedra acus & 1 & 0.023 \\
Synura.sp. & 1 & 0.062 \\
Scenedesmus quadricauda & 1 & 0.058 \\
\hline
\end{tabular}

Table 6. Common species of phytoplankton in autumn in Taihu National Wetland Park

\begin{tabular}{c|c}
\hline Phylum & Species \\
\hline Cyanophyta & $\begin{array}{c}\text { Merismopedia minima } \\
\text { Aphanizomenon flosaquae }\end{array}$ \\
\hline Bacillariophyta & $\begin{array}{c}\text { Synedra acus } \\
\text { Cyclotella meneghiniana }\end{array}$ \\
\hline Chrysophyta & Synura.sp. \\
\hline Chlorophyta & Ankistrodesmus angustus \\
& Scenedesmus quadricauda \\
\hline
\end{tabular}

\section{Relationship between environmental variables and some major phytoplankton species}

RDA was carried out to determine the relationship between the abundance of the main functional species (Table 7) and environmental factors. The Monte Carlo test was significant for the first axis and all canonical axes $(p<0.001)$, suggesting that these environmental variables are important factors in explaining the group compositions. From Figure $5, \mathrm{NO}_{3}{ }^{-} \mathrm{N}(0.8692)$ was the main positive correlation factor, $\mathrm{TP}(0.7523)$ was the second main positive correlation factor, and $\mathrm{NH}_{4}^{+}-\mathrm{N}(0.6867)$ and $\mathrm{COD}_{\mathrm{Cr}}(0.5641)$ also had significant positive correlation, while $\mathrm{pH}(-0.7595)$ in negative correlation factors had significant correlation. Water temperature (WT) was weakly but positive related to most of the phytoplankton species. From Figure 6, temperature and $\mathrm{pH}$ did not differ 
significantly between the sites, therefore, these parameters could not influence the community structure.

Table 7. Species and numbers of phytoplankton in the RDA ordination chart

\begin{tabular}{c|c|c|c}
\hline No. & Latin name & No & Latin name \\
\hline L1 & Merismopedia minima & Y1 & Cryptomonas ovate \\
L2 & Merismopedia marssonii & LU1 & Euglena oxyuris \\
L3 & Phormidium allorgei & LV1 & Chlamydomonas globosa \\
L4 & Aphanizomenon flosaquae & LV2 & Ankistrodesmus angustus \\
G1 & Melosira granulata & LV3 & Scenedesmus quadricauda \\
G2 & Synedra acus & LV4 & Selenastrum minutum (Nag). Coll \\
G3 & Synedra amphicephala & LV5 & Kirchneriella lunaris \\
G4 & Synedra ulna & LV6 & Dictyosphaerium pulchellum \\
G5 & Cyclotella meneghiniana & LV7 & Crucigenia tetrapedia \\
G6 & Navicula exigua & LV8 & Cosmarium obtusatum \\
H1 & Synura.sp. & & \\
\hline
\end{tabular}

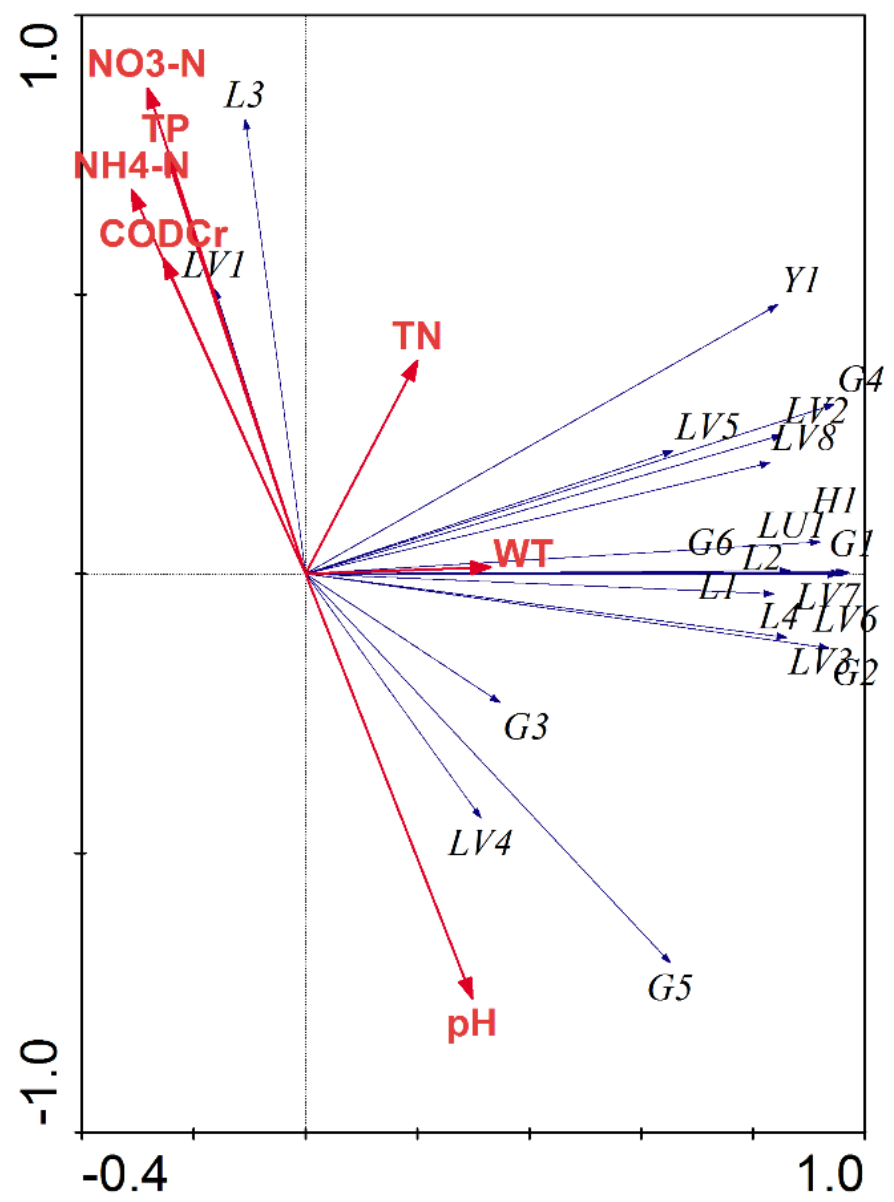

Figure 5. RDA analysis chart of phytoplankton species and environmental factors. Water temperature (WT), pH,total nitrogen (TN), total phosphorus (TP), ammonia nitrogen $\left(\mathrm{NH}_{4}^{+}-\mathrm{N}\right)$ and nitrate nitrogen $\left(\mathrm{NO}_{3}^{-}-\mathrm{N}\right)$ and Chemical Oxygen Demand (CODcr) 


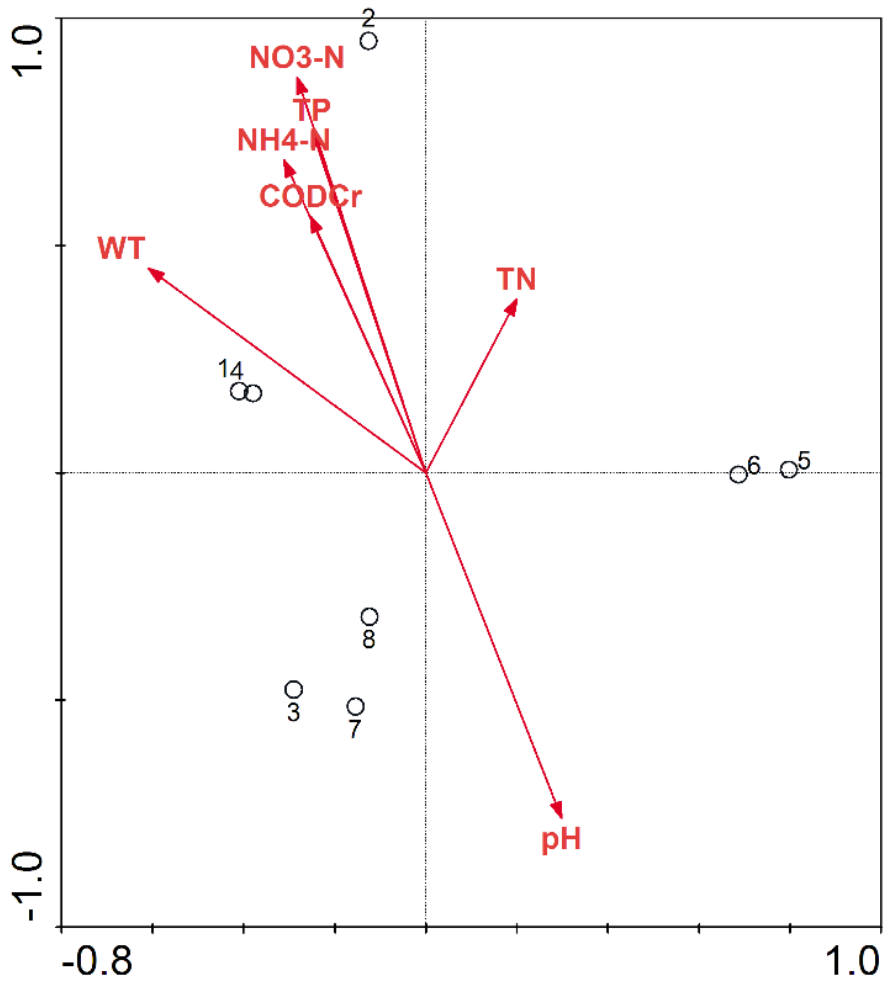

Figure 6. RDA analysis chart of sampling sites and environmental factors. Water temperature (WT), pH,total nitrogen (TN), total phosphorus (TP), ammonia nitrogen $\left(\mathrm{NH}_{4}^{+}-\mathrm{N}\right)$ and nitrate nitrogen $\left(\mathrm{NO}_{3}^{-}-\mathrm{N}\right)$ and Chemical Oxygen Demand (CODcr).

\section{Discussion}

Variables such as dissolved gases, water temperature, $\mathrm{pH}$, phosphates, nitrates, conductivity among many others including various physical properties (gases and solids solubility) are very important for growth and dispersal of phytoplankton (Mahar et al., 2000; Toma, 2011; Ma et al., 2019). Water temperature which is one of the important variables that influence growth of phytoplankton communities in aquatic system did not differ significantly. Water temperature not only influences the growth and distribution of phytoplankton in aquatic ecosystems, but also influences solubility of gases, water stratification, conductivity and $\mathrm{pH}$ (Sharm and Michael, 1987). The measured $\mathrm{pH}$ of lake varied between 8.25 to 9.32 during the study period. The values showed that the water of Taihu National Wetland Park was alkaline in nature.

Nutrients, especially phosphorus and nitrogen, are important for healthy growth of phytoplankton in aquatic systems. Plant can absorb nitrogen both as nitrate and ammonia. The concentrations of ammonia nitrogen, total nitrogen and total phosphorus went beyond class IV requirements of Environmental Quality Standards for Surface Water (National standards of the People's Republic of China) (GB3838-2002). The concentration data of total nitrogen and total phosphorus exceeded the limit values of eutrophication indicators proposed by OECD. Spatially, sites $2 \#$ and $3 \#$ had significant higher values of the nutrients concentration. This could be attributed by the fact that the site was located on a sewage treatment plant. Sites $5 \#$ to $8 \#$ recorded the lowest concentration values of nutrients probable because they were located within the wetland where the wetland plants and soil acted as filters of the nutrients. 
In aquatic ecosystem, phytoplankton community structure often changes with the change of environment factors (Ouyangxb and Han, 2007; Li et al., 2014). Diversity indices has often been used to evaluate water pollution and phytoplankton community status. In this study, Shannon Weaver diversity index $\left(H^{\prime}\right)$ was used to assess the diversity of phytoplankton spatial and also see whether environmental factors had an impact on the community structure. The study showed that the diversity index ranges from 1.041 to 2.371 , with an average of 1.486. Species richness measured in this study ranged from 0.838 to 3.665 , with an average of 1.7 . Sites $5 \#$ and 6\# which were light and medium polluted respectively had high diversity and richness values. According to the Intermediate Disturbance Hypothesis (IDH) theory, high diversity occurs at sites experiencing moderate levels of disturbance due to competition hierarchy of species. At low levels of disturbance or pollution, more competitive organisms will push subordinate species to extinction and dominate the ecosystem hence low diversity (Dial and Roughgarden, 1998). Those sites which were located far away from where the sewage treatment plant was had low phytoplankton diversity and richness. This implies that the distribution of phytoplankton species in Taihu National Wetland Park is uneven and the stability of community structure is unstable. Moreover, the fact that Schizosaccharum tenuiflorum, filamentous alga bloom and Scenedesmus giraldii were dominant implies that this wetland park could be facing serious pollution and also the concentration of organic matter is high (Liang et al., 2019).

The relationships between environmental variables and phytoplankton species were determined in this study. Water temperature (WT) was positively related to the abundance and biomass of the most phytoplankton species. According to Srifa (2010), water temperature is a factor that can positively or negatively affect the growth of some plankton species. Moreover, the rate of photosynthesis of phytoplankton is promoted by the rising water temperature, which accelerates the accumulation of biomass (Gong et al., 2020). The growth rate of phytoplankton is generally low in acidic water and higher in weak alkaline water (You et al., 2007). In this study, the $\mathrm{pH}$ value fluctuated from 8.25 to 9.32, which was beyond the $\mathrm{pH}$ value range of weak alkaline water, which might likely limit the growth and development of phytoplankton. Moreover, the results of RDA analysis showed that there was a significant negative correlation between $\mathrm{pH}$ and Synedra amphicephala, Cyclotella meneghiniana and Selenastrum minutum (Nag). Coll, which was consistent with the above phenomenon.

Nutrient enrichment will stimulate the growth of phytoplankton in relation to its abundance and biomass in various aquatic systems. Phytoplankton in different plant classes have different requirement for nutrition of phosphorus and nitrogen. Nitrogen species such as nitrate, nitrite and ammonia nitrogen, which are equilibrated with each other, can also affect phytoplankton community structure. The results of RDA analysis showed that there was a significant positive correlation between sampling site $2 \#$ and $\mathrm{NO}_{3}^{-}-\mathrm{N}$ (Fig. 6), and the dominant species in this sampling site, Phormidium allorgei and Chlamydomonas globosa, also showed a significant positive correlation with $\mathrm{NO}_{3}^{-}-\mathrm{N}$ and TP. This may be due to the fact that sampling site $2 \#$ is located in a sewage treatment plant with serious nitrogen and phosphorus pollution, and its ecological environment is conducive for the growth and development of Phormidium allorgei and Chlamydomonas globosa, which can be used as indicator species for mesotrophic-eutrophic water. Nutrients such as $\mathrm{N}$ and $\mathrm{P}$ are important for the growth of phytoplankton, and at particular concentrations can influence the growth of phytoplankton (Elmgren and Larsson, 2001). Sun et al. (2008) note that increase concentrations of $\mathrm{N}$ and $\mathrm{P}$ at a given range can promote 
the growth of phytoplankton. This, therefore implies that nutrients factors in the wetland can effectively control the abundance and biomass of phytoplankton species through bottom-up effects.

\section{Conclusion}

In this study, a total of 39 species of phytoplankton were detected in Taihu National Wetland Park and Cyanophyta was dominant in some areas. The dominant species of phytoplankton in this survey are Merismopedia minima and Aphanizomenon flosaquae of Cyanophyta, Synedra acus of Bacillariophyta, Synura.sp. of Chrysophyta and Scenedesmus quadricauda of Chlorophyta. According to the evaluation of water quality based on physical and chemical indexes and phytoplankton diversity indexes, Taihu National Wetland Park is generally moderately to severely polluted, especially near the outlet of sewage treatment plant. Water temperature, nitrogen and phosphorus nutrients, and $\mathrm{pH}$ value are the key factors affecting phytoplankton community structure. Therefore, the above-mentioned environmental factors should be considered in the future treatment of water pollution in Taihu National Wetland Park.

Acknowledgements. The authors are grateful to the people that helped with all aspects of the fieldwork. This study was supported by the central government supports the reform and development fund projects of local colleges and universities "Research on integrated technology innovation of sustainable utilization of cold water fish resources industrialization" (2020GSP14), and Key research topics of economic and social development in Heilongjiang Province (20309).

\section{REFERENCES}

[1] Cardinale, B. J., Duffy, J. E., Gonzalez, A., Hooper, D. U., Perrings, C., Venail, P., Narwani, A., Mace, G. M., Tilman, D., Wardle, D. A. (2012): Biodiversity loss and its impact on humanity. - Nature 486: 59-67.

[2] Chalar, G. (2009): The use of phytoplankton patterns of diversity for algal bloom management. - Limnologica 39: 200-208.

[3] Chen, N., Wang, Y., Yang, T., Yu, H., Ma, C. (2018): Characteristics of functional group and evaluation of water quality of summer phytoplankton in the Tai Lake. - Journal of Northeast Forestry University 46: 69-73. (in Chinese with English abstract).

[4] Clarke, K. R., Warwick, R. M. (1994): Change in marine communities: an approach to statistical analysis and interpretation. - United Kingdom: Plymouth marine laboratory, Natural environment research council.

[5] Dial, R., Roughgarden, J. (1998): Theory of marine communities: the intermediate disturbance hypothesis. - Ecology 79: 1412-1424.

[6] Elmgren, R., Larsson, U. (2001): Nitrogen and the Baltic Sea: managing nitrogen in relation to phosphorus. - The Scientific World Journal 1: 371-377.

[7] Gong, F., Li, G., Wang, Y., Liu, Q., Huang, F., Yin, K., Gong, J. (2020): Spatial shifts in size structure, phylogenetic diversity, community composition and abundance of small eukaryotic plankton in a coastal upwelling area of the northern South China Sea. - Journal of Plankton Research 42: 650-667.

[8] Hu, H. (2006): The freshwater algae of China: systematics, taxonomy and ecology. Science Press.

[9] Li, H., Liu, Y., Fan, Y., Guo, C. (2014): Community structure characteristics of phytoplankton in Tongjiang of the Sanjiang Plain Wetland. - Chinese Bulletin of Botany 49: 440. (in Chinese with English abstract). 
[10] Liang, Y., Zhang, G., Wan, A., Zhao, Z., Wang, S., Liu, Q. (2019): Nutrient-limitation induced diatom-dinoflagellate shift of spring phytoplankton community in an offshore shellfish farming area. - Marine pollution bulletin 141: 1-8.

[11] Lin, Z. (2002): Analysis of Water Environmental Change in Taihu Watershed. - Journal of Lake Science 14: 111-116. (in Chinese with English abstract).

[12] Ma, C., Yu, H. (2013): Phytoplankton community structure in reservoirs of different trophic status, Northeast China. - Chinese journal of oceanology and limnology 31: 471481.

[13] Ma, C., Chula, M. P., Yu, H., Sun, X., Liang, L., Al-Ghanim, K., Mahboob, S. (2019): Spatial and temporal variation of phytoplankton functional groups in extremely alkaline Dali Nur Lake, North China. - Journal of Freshwater Ecology 34: 91-105.

[14] Ma, C., Zhao, C., Mwagona, P. C., Li, Z., Liu, Z., Dou, H., Zhou, X., Bhadha, J. H. (2021): Bottom-up and top-down effects on phytoplankton functional groups in Hulun Lake, China. - In: Annales de Limnologie-International Journal of Limnology, EDP Sciences, p. 3.

[15] Mahar, M., Baloch, W., Jafri, S. (2000): Diversity and seasonal occurrence of planktonic rotifers in Manchar Lake, Sindh, Pakistan. - Pakistan Journal of Fisheries 1: 25-32.

[16] MEP. (2002): China's national standard: GB3838-2002: Environmental quality standards for surface water. - Ministry of Environmental Protection C.

[17] Mulvenna, V., Dale, K., Priestly, B., Mueller, U., Humpage, A., Shaw, G., Allinson, G., Falconer, I. (2012): Health risk assessment for cyanobacterial toxins in seafood. International journal of environmental research and public health 9: 807-820.

[18] Oduor, S., Schagerl, M. (2007): Phytoplankton photosynthetic characteristics in three Kenyan Rift Valley saline-alkaline lakes. - Journal of Plankton Research 29: 1041-1050.

[19] Oren, A. (2011): Thermodynamic limits to microbial life at high salt concentrations. Environmental microbiology 13: 1908-1923.

[20] Ouyangxb, H., Han, B. (2007): Water quality and phytoplankton community in the Qiyeshi Reservoir after water diversion from Dongjiang River. - Journal of Lake Sciences 19: 204211.

[21] Schagerl, M., Oduor, S. (2008): Phytoplankton community relationship to environmental variables in three Kenyan Rift Valley saline-alkaline lakes. - Marine and Freshwater Research 59: 125-136.

[22] Shannon, C. E., Weiner, W. (1948): A mathematical theory of communication. - Publ. University of Illinois Press, Urbana.

[23] Sharm, B., Michael, R. G. (1987): Review of taxonomic studies on freshwater Cladocera from India with remarks on biogeography. - Hydrobiologia 145: 29-33.

[24] Shi, Y. Q., Sun, S., Zhang, G. T., Wang, S. W., Li, C. L. (2015): Distribution pattern of zooplankton functional groups in the Yellow Sea in June: a possible cause for geographical separation of giant jellyfish species. - Hydrobiologia 754: 43-58.

[25] Srifa, A. (2010): Factors controlling zooplankton dynamics in a subtropical lake during cyanobacterial bloom events. - University of Florida.

[26] Sun, X., Dong, S., Tang, Z. (2008): Influences of nutrients and illuminace on phytoplankton community structure. - South China Fish Sci. 4: 5-13. (in Chinese with English abstract).

[27] Sun, S., Huo, Y., Yang, B. (2010): Zooplankton functional groups on the continental shelf of the yellow sea. - Deep Sea Research Part II: Topical Studies in Oceanography 57: 10061016.

[28] Sun, X., Mwagona, P. C., Shabani, I. E., Hou, W., Li, X., Zhao, F., Chen, Q., Zhao, Y., Liu, D., Li, X. (2019): Phytoplankton functional groups response to environmental parameters in Muling River basin of northeast China. - In: Annales de LimnologieInternational Journal of Limnology. EDP Sciences, p. 17.

[29] Toma, J. J. (2011): Physical and chemical properties and algal composition of Derbendikhan lake, Sulaimania, Iraq. - Current World Environment 6: 17-27. 
[30] Weyhenmeyer, G. A., Peter, H., Willén, E. (2013): Shifts in phytoplankton species richness and biomass along a latitudinal gradient-consequences for relationships between biodiversity and ecosystem functioning. - Freshwater Biology 58: 612-623.

[31] Yang, M., Bi, Y., Hu, J., Zhu, K., Zhou, G., Hu, Z. (2011): Seasonal variation in functional phytoplankton groups in Xiangxi Bay, Three Gorges Reservoir Chinese. - Journal of Oceanology and Limnology 29: 1057-1064.

[32] You, L., Cui, L., Liu, Z., Yang, B., Huang, Z. (2007): Correlation analysis of parameters in algal growth. - Environmental Science \& Technology 30: 42-44. 
Chai et al.: Phytoplankton community structure and its relationship with environmental factors in Taihu National Wetland Park in northeast China

$$
-4402 \text { - }
$$

\section{APPENDIX}

Appendix 1. List of phytoplankton in Taihu National Wetland Park

\begin{tabular}{|c|c|c|c|}
\hline Phylum & Family & Genus & Species \\
\hline \multirow[t]{4}{*}{ Cyanophyta } & Merismopediaceae & Merismopedia & Merismopedia minima \\
\hline & & & Merismopedia marssonii \\
\hline & Phormidioideae & Phormidium & Phormidium allorgei \\
\hline & Nostocaceae & Aphanizomenon & Aphanizomenon flosaquae \\
\hline \multirow{11}{*}{ Bacillariophyta } & Fragilariaceae & Fragilaria & Fragilaria brevistriata \\
\hline & & Synedra & Synedra acus \\
\hline & & & Synedra amphicephala \\
\hline & & & Synedra ulna \\
\hline & & Diatoma & Diatoma vulgare \\
\hline & Coscinodiscaceae & Melosira & Melosira granulata \\
\hline & & Cyclotella & Cyclotella meneghiniana \\
\hline & Naviculaceae & Navicula & Navicula exigua \\
\hline & & & Navicula dicephala \\
\hline & Gomphonemaceae & Gomphonema & Gomphonema constrictum \\
\hline & Cymbellaceae & Cymbella & Cymbella ventricosa \\
\hline \multirow[t]{2}{*}{ Euglenophyta } & Euglenaceae & Euglena & Euglena oxyuris \\
\hline & & Strombomonas & $\begin{array}{l}\text { Strombomonas } \\
\text { schauinslandii }\end{array}$ \\
\hline \multirow[t]{20}{*}{ Cyanophyta } & Chlamydomonadaceae & Chlamydomonas & Chlamydomonas globosa \\
\hline & Chlorellaceae & Ankistrodesmus & Ankistrodesmus angustus \\
\hline & & & Ankistrodesmus acicularis \\
\hline & & & Ankistrodesmus falcatus \\
\hline & & Chodatella & Chodatella quadriseta \\
\hline & & Selenastrum & Selenastrum gracile \\
\hline & & & $\begin{array}{l}\text { Selenastrum minutum (Nag). } \\
\text { coll }\end{array}$ \\
\hline & & Kirchneriella & Kirchneriella lunaris \\
\hline & Scenedesmaceae & Scenedesmus & Scenedesmus bijuga \\
\hline & & & Scenedesmus dimorphus \\
\hline & & & Scenedesmus quadricauda \\
\hline & & & Scenedesmus platydiscus \\
\hline & & Coelastrum & Coelastrum microporum \\
\hline & & Crucigenia & Crucigenia quadrata \\
\hline & & & Crucigenia tetrapedia \\
\hline & Volvocaceae & Pandorina & Pandorina morum \\
\hline & Pediastraceae & Pediastrum & Pediastrum birtadiatum \\
\hline & & & Pediastrum tetras \\
\hline & Dictyosphaeraceae & Dictyosphaerium & Dictyosphaerium pulchellum \\
\hline & Desmidiaceae & Cosmarium & Cosmarium obtusatum \\
\hline Chrysophyta & Synuraceae & Synura & Synura.sp \\
\hline Cryptophyta & Cryptomonadaceae & Cryptomonas & Cryptomonas ovata \\
\hline
\end{tabular}

